\title{
A CASE STUDY IN DOCUMENTATION PRODUCTION AS LEARNING TOOLS BENEFITTING MULTIPLE STAKEHOLDERS
}

\author{
T.J. Truesdale ${ }^{\mathrm{a}}$, B.Hierlihy ${ }^{\mathrm{b} *}$, P. Jouan ${ }^{\mathrm{c} *}$ \\ ${ }^{\text {a }}$ Fondation Strutt Foundation, Ottawa ON Canada - titania@ struttfoundation.ca \\ b PTAH Consultants Inc., Architects, Spencerville, ON Canada, Hierlihy@ptah.ca \\ ${ }^{c}$ Raymond Lemaire International Centre for Conservation, KU LEUVAN, 3001 Leuven, Belgium - pierre.jouan@asro.kuleuven.be
}

\section{Commission II}

KEY WORDS: Heritage, Documentation, Surveys, Structure Report, Building Simulation, Building Information Modelling BIM, Conservation Planning, Conservation Management Plan

\begin{abstract}
:
The Fondation Strutt Foundation has taken on the conservation planning of the Strutt House as part of a P3 collaborative effort with the National Capital Commission (NCC). This paper will address three of the primary documents/data sets (documentary methodologies) being used on/for the Strutt House project. The Strutt House is a Recognized Federal Heritage Building and a significant example of Canadian modernist architecture. Stakeholder is a term often used in Architectural Projects reflecting an economic interest in success of the project. In conservation projects the stakeholder generally reflects social, cultural and/or economic interests in a given project. The Strutt House project has benefitted from stakeholders that have all been interested in the above, as well as the education of our future conservationists. The Strutt house was purchased from the architect's daughter in 2010 , and as part of the acquisition, a Heritage Structure Report was commissioned and produced by PTAH Consultants Inc., Architects. The report forms the first of the primary referenced documents of this paper, including: a comprehensive photographic record of existing conditions; and, a building simulation model of the house 'as designed/built'. This HSR and the accompanying data/documents have been adopted as the basis of an evolving document in the development of the Conservation Plan including: additional heritage surveys and technologies; traditional drawings, photographic and video records; and, a series of workshops on the structural stabilization efforts, thermography scans, and smoke/blow-door (air pressure) testing. In 2016, Pierre Jouan, a Master's thesis student from KU Leuvan, working with the Carleton University CIMS lab under the direction of Professor Mario Santana, and the FSF completed a 3-D scanning and photogrammetry workshop on the Strutt House and created a building information model (BIM model) from the collected data. The three primary documentation processes being addressed in this paper are really a series of directed research or focussed investigations resulting in a collection of data sets resolved -or combined- into a document. They will assist in the development of the long-term Programming and Conservation Management Plan of the Strutt House.
\end{abstract}

\footnotetext{
* Corresponding author
} 


\section{STAKEHOLDERS}

Stakeholder is a term often used in Architectural Projects reflecting an economic interest in success of the project. In conservation projects the stakeholder generally reflects social, cultural and/or economic interests in a given project. The Strutt House project has benefitted from stakeholders that have all been interested in the above, as well as the education of our future conservationists. We consider ourselves fortunate to be working with all of the following.

\subsection{National Capital Commission}

The National Capital Commission (NCC) is a federal Crown corporation of the Government of Canada mandated to fulfil three specific roles: long-term planner of federal lands, principal steward of nationally significant public places, and creative partner committed to excellence in development and conservation.

\subsection{Fondation Strutt Foundation}

The Fondation Strutt Foundation (FSF) supports projects and individuals that make meaningful contributions to critical modernist architectural discovery and discourse through research, education, and conservation efforts of Modern Architectural heritage within central Canada. The FSF responded to a Request for Expressions of Interest from the National Capital Commission, with a proposal to work toward the conservation of the property.

\subsection{PTAH Consultants Inc., Architects}

PTAH Consultants Inc., Architects is an architectural practice with a focus on heritage conservation and stewardship issues. In the fall of 2011, PTAH was commissioned by the NCC to complete a comprehensive investigation of the Strutt House, resulting in the Strutt House Heritage Structure Report (HSR). Brian Hierlihy, the Founding/Managing Director of PTAH, is also the Lead Architect and a Member of the FSF Strutt House Project Advisory Committee.

\subsection{Carleton University, CIMS}

Carleton University is a comprehensive university located in Ottawa, Ontario, Canada. Carleton Immersive Media Studio (CIMS) is a research unit of the Azrieli School of Architecture \& Urbanism, researching the relationships between the digital, physical and built modes of representation in Architecture, and the advancement and development of the tools, processes and techniques involved in the transformation of data into meaningful artefacts.

\subsection{Additional Documentation Beneficiaries}

There have been many additional organizations involved in the documentation of the Strutt House Project. As an educational support and research organization, many students have also been involved in several of the activities on site. All the following organisations have produced some sort of documentation specific to their area of interest in the project. They are noted here for context only.

1.5.1 Parks Canada: The Federal Heritage Building Review Office (FHBRO) is responsible for advising government departments on their heritage obligations under Treasury Board Policy. The NCC requested a FHBRO report on the Strutt house and it was designated as 'Recognized' February $9^{\text {th }}$, 2011(Reference 09-277). Requests to FSF for documentation and information on the house from Parks Canada were addressed coincidental to the HSR. The initial FHBRO draft report was available just prior to the completion of the HSR, additional photographic documentation was created for the on-line Directory of Federal Heritage Designations.

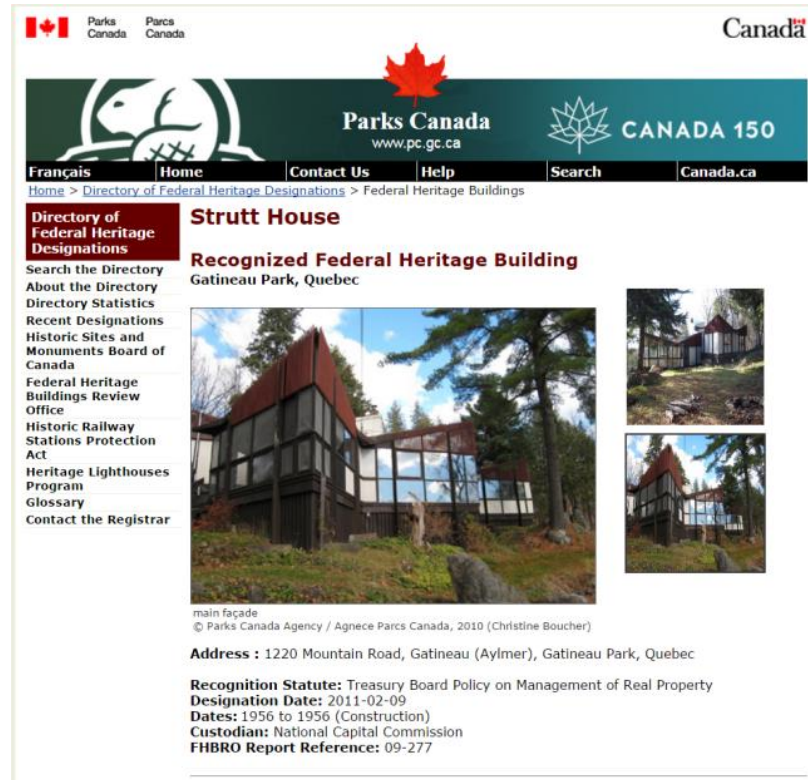

Date Modified : 2012-03-15

Important Notices

Figure 1. Screen capture of $\odot$ Parks Canada web page from their Directory of Federal Heritage Designations

1.5.2 The Getty Foundation: The Getty Foundation is an additional stakeholder in the project as the funds to produce the Conservation Plan (CP) were granted to the FSF through their \#KeepingItModern Initiative. The CP and many of the research results discovered in the process of the development of the $\mathrm{CP}$ have been/will be shared with the Getty, other grant recipients, and the public at large through the Getty Institute.

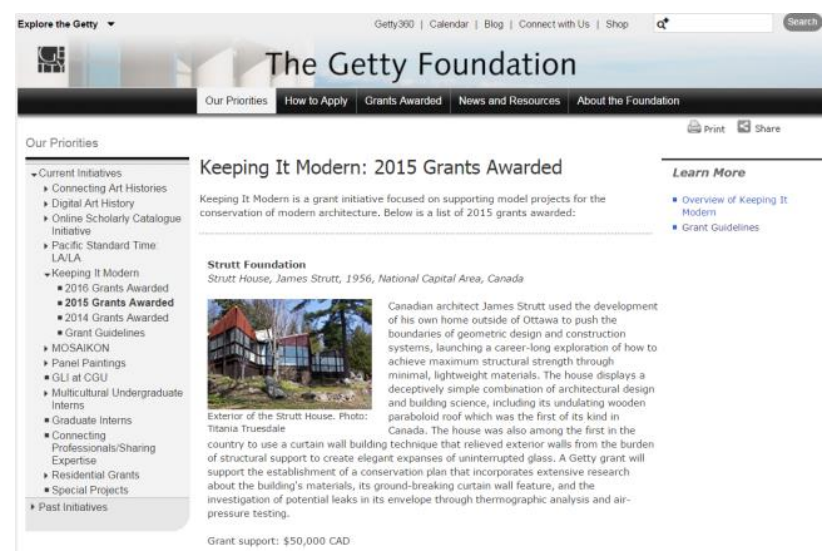

Figure 2. Screen capture $\odot$ Getty Foundation web page of Keeping It Modern 2015 Grant Awards

1.5.3 Algonquin College: The Centre for Construction Excellence and the Centre for Applied Research \& Innovation supported the FSF with three 'International Scholars' to work 
on the initial building and site stabilization. All work was recorded, with photo-documentation, weekly site reports, and monthly reports and presentations to the Advisory Committee. The School of Applied Science \& Environmental Technology had a team of students who produced a Surface Water Runoff Feasibility Study that included site survey documentation, research and proposed design scenarios for erosion mitigation and accessibility. This fall we have a Building Science Practicum Student, conducting research/testing to compile a report related to sustainability features, energy consumption, the weight efficiency structure, and the building envelopes passive solar hybrid curtain wall.

1.5.4 Carleton University: In addition to the CIMS lab contribution to the documentation of the Strutt House site (covered in more depth in the next section) several Schools/Faculties have been involved in producing documentation of and at the Strutt House.

1. Sprott School of Business, School of Public Policy and Administration, Sprott Centre for Social Enterprise: Masters Students in the Finances for Philanthropy and the Nonprofit Sector produced Case Study Resource Models Reports.

2. Azrieli School of Architecture, BAS Conservation \& Sustainability, and BAS Design: Many students from multiple programs of the school have been involved in hands-on stabilization workshops and or assigned the Strutt House as a design research project. 3. Faculty of Engineering, Department of Civil and Environmental Engineering (Architectural Conservation and Sustainability Engineering) fourth year students produced an adaptive reuse proposal for the Strutt House. The project addressed architectural conservation and structural engineering issues. (HODI Award winning project).

4. School for Studies in Art \& Culture: Art History, History and Theory of Architecture Program. One undergrad and one Masters student fulfilled their Practicum studies with the FSF and participated in research and documentation of exhibit materials for the Strutt House's role as one of the official 2017 Confederation Pavilions of the NCC and associated exhibitions at the Gatineau Park Visitors Centre Mason Gallery.

\section{DOCUMENTATION}

The three primary documentation processes being addressed in this paper are really a series of directed research or focussed investigations resulting in a collection of data sets resolved -or combined- into a document.

\subsection{Heritage Structure Report (HSR)}

PTAH Consultants Inc., Architects (PTAH) was retained by the National Capital Commission (NCC) to undertake an asset condition analysis (aka building condition report) of the residence of Canadian architect James Strutt. The purpose of the work was to investigate and document the condition of the property, code compliance concerns, and matters related to fitness for purpose.

Submitted to the NCC in 2011, it is a comprehensive investigation/report on findings of the building as the NCC bought it. Although prepared by a professional firm rather than students, it serves as the project reference document, and has become a very useful teaching tool for all subsequent activities.

\subsubsection{HSR Methodology}

The investigative work included:

1 identification and examination of historical records relating to the development of the premises,

2 examination of the premises, including mechanical and electrical systems,

3 interviews with individuals involved with the building as-required to clarify the history of site use and development,

4 development of a computer simulation of the as-found condition to confirm and document the observed construction, and to provide a basis for intervention proposals, and

5 minor destructive investigations where required to facilitate analysis of the building fabric and/or failures in the fabric.

The reporting work resulted in the document, including:

1 documentation of the background and overall condition of the building envelope,

2 a building simulation that describes the building construction and from which drawings and illustrations have been developed,

3 a comprehensive photographic catalog of the building,

4 recommendations regarding the design of the proposed renovation, and

5 probable construction cost estimates related to the recommended interventions.

\subsubsection{HSR to Strutt House Project Guidance Document}

The HSR produced by PTAH Consultants Inc., Architects $(\mathrm{PTAH})$ serves as the foundation document for most of the planning and activities that have taken place on the Strutt House site over the last five years.

Donated to, and adopted by the FSF as the project document of the Strutt House Project, it has become a living document subject to peer review/input from the Advisory Committee as well as all Architectural, Engineering and Heritage professions involved in the project.

The HSR has already been used to initiate various activities including: creating educational workshops, developing tours, 'winterization and stabilization' activities, and catching up on all the 'deferred maintenance' activities. At the end of the project it is anticipated that it will include the various stages or 'states' of the house as the project evolves, from the original report condition, 'as is' conditions as the deferred maintenance and stabilization activities are completed, and ultimately the completion of the conserved property.

The HSR continues to be expanded upon and the iterative releases capture the progress of the project and reflect the current condition of the building with each period of production. This has assisted the FSF to document the process of the project. It has also been the primary research/source document for teaching about the building, in the production of the developing Conservation Plan, and primary resource for the Thesis research carried out by Mr Pierre Jouan and the CIMS lab (see para 2.2 below). 


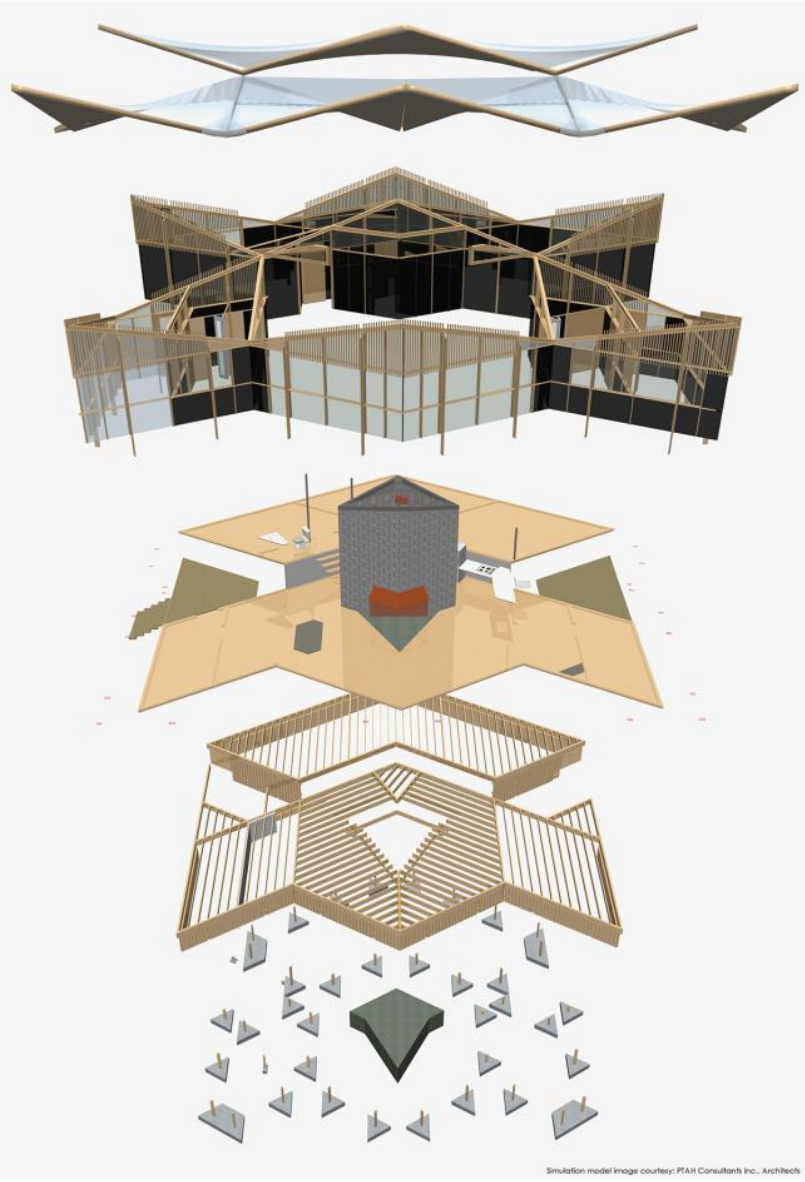

Figure 3. Image extraction from Building Simulation Model of the HSR (CPTAH Consultants Inc. Architects)

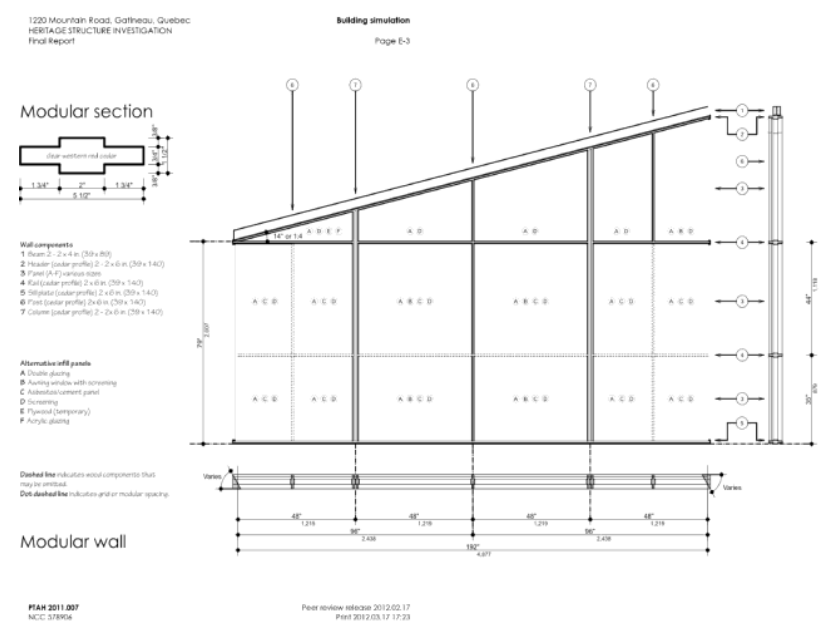

Figure 4. Image of Structural building elements from the HSR (CPTAH Consultants Inc. Architects)
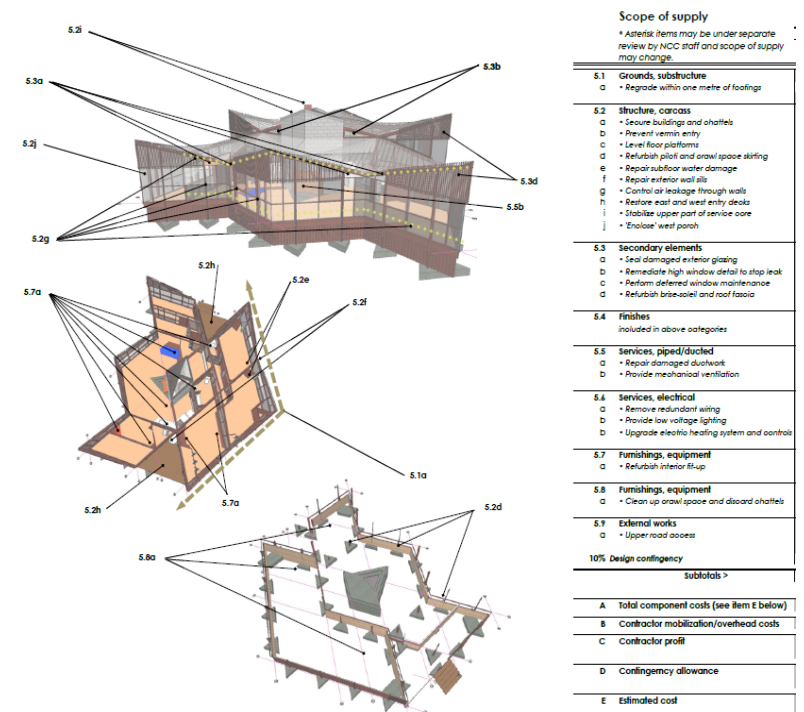

Figure 5. The HSR use of the building simulation model (@PTAH Consultants Inc. Architects)

\subsection{FSF and CIMS Collaboration: a Thesis}

The FSF was approached by Carleton's Professor Mario Santana and Leuvan University Masters Thesis student Pierre Jouan regarding the possibility of using the Strutt House as a possible venue for a thesis investigation using 3-D scanning and photogrammetry to produce a Building Information Model of the existing as-is conditions. Mr Jouan was working with the CIMS lab as well and it was determined it would be an excellent opportunity for all parties. The research from his thesis is worthy of another paper for this symposium, but the benefits gained for all parties involved is the focus here.

\subsubsection{Survey Methodology}

According to Pierre Jouan's thesis "Building Information Modeling and the conservation of small scale wooden composite structures, learning from the case study of the "Strutt House":

"The first step that was undertaken was to read the Heritage Structure Report, the condition assessment done in 2012 by "PTAH Consultants Inc., Architects".

Before starting the Strutt House's survey, several sites visits were necessary to develop an insight into the realization of the building. It was deemed important to understand how the building was actually designed and what where the concepts behind it, to establish clear goals for the documentation.

Mr Jouan developed a 'Knowledge-based strategy' as a way to analyse the information collected and to help define his thesis focus.

For the survey itself, it was then necessary to determine the graphic documents that would have to be produced as well as their scale and level of detail. The tools and techniques to be used to record the data could then be chosen. Finally, before starting the survey, very accurate planning was required in order to optimize the time spent on site and avoid recording repetitive data. Because the built-in furniture and the partition of the spaces, hand measurements were still required to document details of partitions/bespoke furniture, as well as to complete documentation in some smaller areas that could not be captured 
by the scanner. Later on, this would help to complete the model created from the point cloud.

\section{METHODOLOGY}
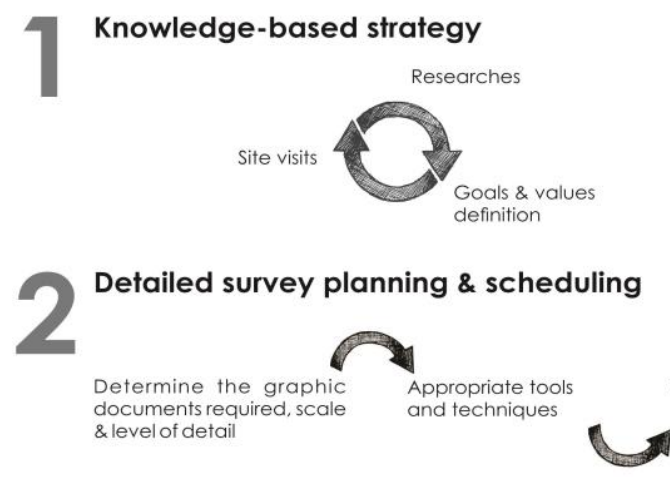

Survey planning
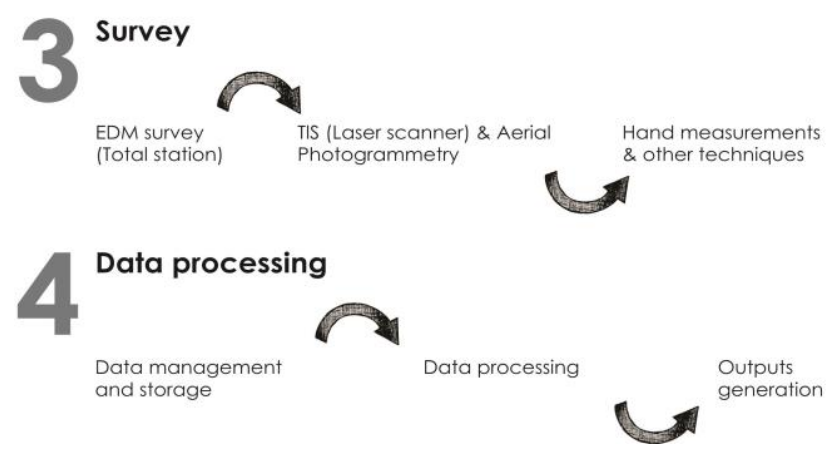

Figure 6. Scheme of the methodology followed for the survey of the Strutt House, by Pierre Jouan.

\subsubsection{Site Surveys}

In collaboration with CIMS and Professor Santana, a series of workshops on 3-D laser scanning were undertaken on site at the Strutt House. Besides the laser scanner it was also necessary to bring the total station on site so as to register control points. The latter allowed the geo referencing of all the scans either from the drone or from the laser scanner.

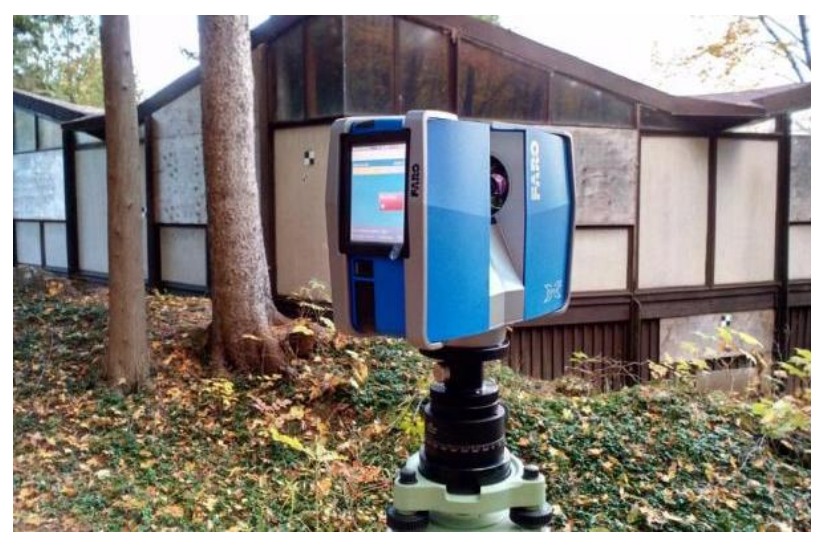

Figure 6. Laser scanning the building with a Faro Laser Scanner Focus3D X330 (above) Photo: Pierre Jouan.

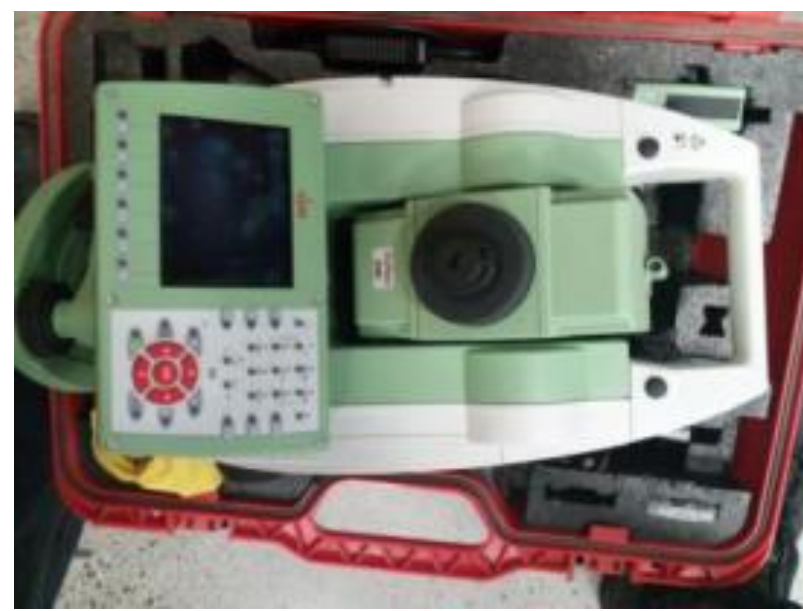

Figure 7. Leica viva TS11, Total Station. Photo: Pierre Jouan.

2.2.5 As the roof was one of the most interesting structural elements of the building, it was essential to properly document it to properly analyze it. It was decided to use aerial photogrammetry, with a drone, to achieve this task. The goal was to provide a point cloud that could later be merged with the other scans. The aerial photogrammetry is basically like "normal" photogrammetry with targets placed on the surface, and pictures are taken from above with the drone capturing images of the site from different angles. Later in the project, photogrammetry was processed from these pictures and the point cloud was created.

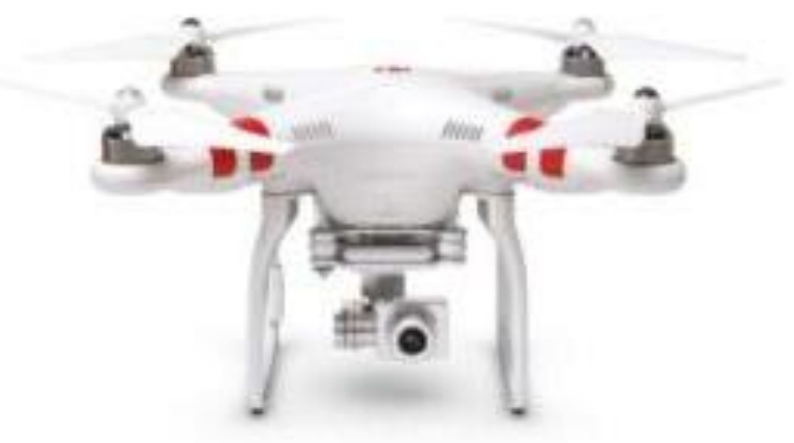

Figure 8. Aerial photogrammetry drone used on site was a Phantom 2 vision + , www.dji.com

\subsubsection{Scans to BIM: Data Processing}

The purpose of Mr Jouan's research was to determine the applicability of these new technologies in the development of Building Information Modelling 'BIM' documentation for use in heritage conservation and to develop a possible method to generate a BIM model from point clouds. As previously stated that is a paper in and of itself, but both difficulties and advantages were discovered. (see Figure 9). 


\section{METHODOLOGY}

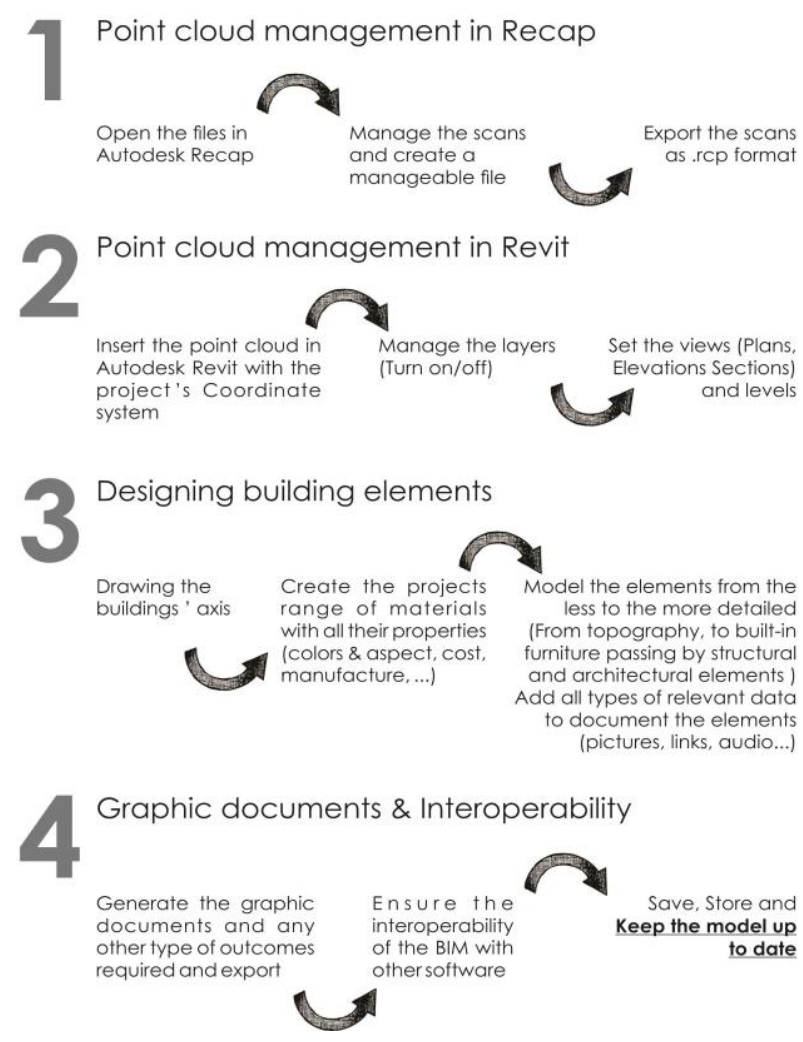

Figure 9. Scheme of the Building Information Modelling (BIM) methodology for the Strutt House, by Pierre Jouan.

\subsubsection{Thesis Findings}

One of the primary issues Mr Jouan discovered working with BIM model in the context of this Heritage Conservation project was the differences to new construction. In this case, it is almost impossible to model with existing elements (already created in the software) as almost every single piece had to be created. The biggest issue faced during the elaboration of the model were time consumption, definition of the level of detail to achieve as well as how close to reality the model should be.

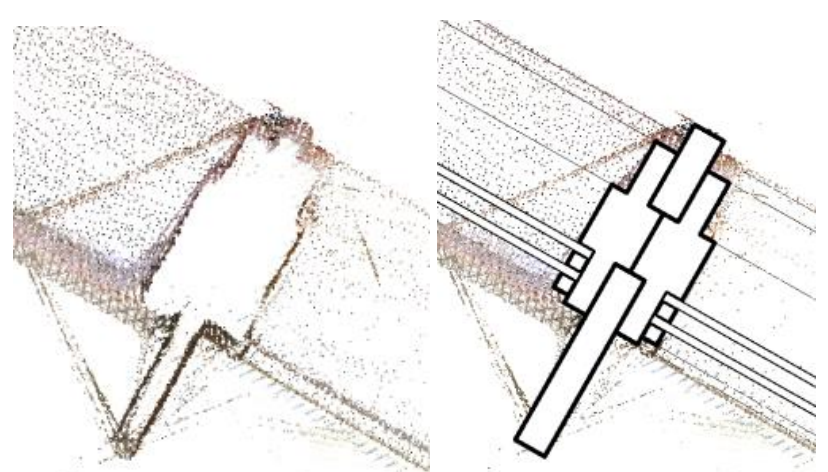

Figur 10. Data captured from the TLS survey (left) and the actual complexity of the structure (right). Pierre Jouan

On the one hand, advantages have been observed especially in terms of data management and visualization, collaborative analysis and design, cost estimation and so on. On the other hand, some features are still not adapted or not present at all in BIM software, and could significantly improve the usefulness of the model for a conservation project. This is particularly true for the condition assessment of buildings.

2.2.4.1 Three benefits determined of working with BIM for Heritage buildings:

1 a better understanding of the asset: the need for modeling each element, defining the exact connections with other building components, and integration of all types of related data requires an in depth comprehension of the original design (in spite of the time required to do so)

2 containing the geometric information related to the building (a kind of 3D database) with the possibility to store many different types of records about construction elements or even simply related to the history of the building.

3 a multi-temporal approach of BIM is another interesting aspect if each element is given a certain date or period of construction in the model's management it is possible to generate several models (either for new project or to illustrate the previous state of the study case) and hide or reveal any step that is required.

It should be noted here that these are similar benefits found in the original Building Simulation created by PTAH.

2.2.4.2 Some possible evolutions suggested for further software developments and improvements.

1 an aspect of BIM that was investigated is the interdisciplinary character of BIM, and it is a very important asset, but adaptations to the software would have to be made in order to adress the needs of Conservation professionals. For instance, the analysis tools present in the software (Structural analysis, Energy and so on) may not be as applicable in BIM models of Heritage buildings due to material age/damage/fatique.

2 there is no tool to map the pathologies or add information about the damages within BIM software. Being able to generate the condition assessment in the same platform would save considerable time by keeping the database central and unique.

3 a condition assessment performed in 3D would lead to a better and clearer understanding of the issues and possible causes of damages. The use of the cost estimation feature could also be even more interesting with such an evolution. As a consequence, estimating the repairs' cost would be much more straightforward.

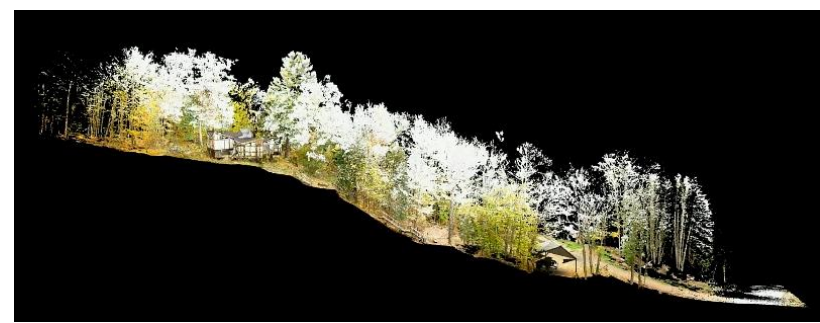

Figure 10. Image of site section from 3-D scan by Pierre Jouan 


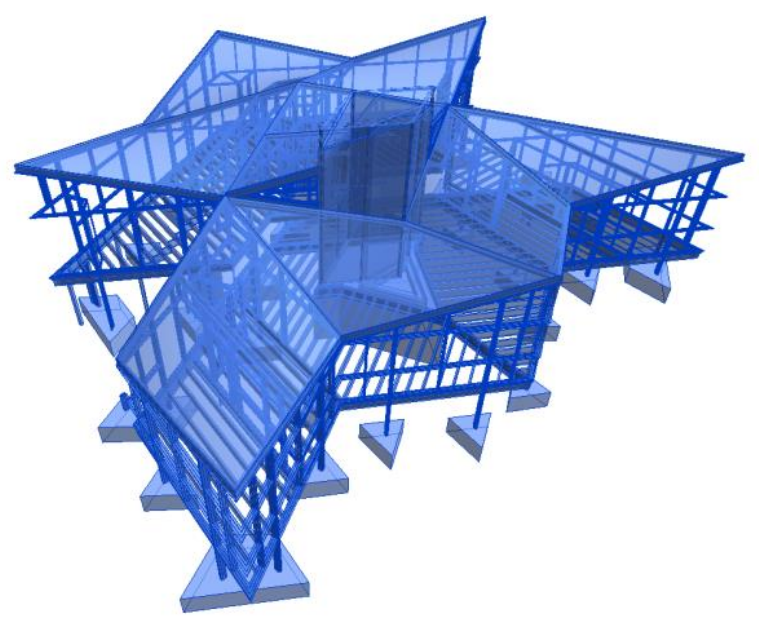

Figure 11. Image of Structural building elements from Pierre Jouan's Thesis Building Information Model (BIM)

\subsection{Strutt Foundation Documentation and Stabilization Workshops}

Workshops organized by the Strutt Foundation, and referred to above, were offered to both undergrad and post graduate students, and were drawn from the recommendations of the HSR and included:

1 Structural levelling of the building (initial jacking of the upper and lower platforms at the piloti locations to horizontally level the floors -an ongoing series of three to four workshops).

2 Smoke test and Blower door test (series),

3 Thermal imaging documentation with two different thermal cameras (series),

4 Moisture content surveys of building's elements with moisture meters, and

5 Roof cavity video capture and metal detection.

6 3-D scanning and Photogrammetry Workshop (with CIMS).

2.3.1 The resulting documentation from each of these workshops are to be compared with the results of the various additional workshops of the same technologies being undertaken during different climatic conditions. These comparisons will help determine the buildings behaviour regarding air and water infiltration, as well as help clarify the priorities for each of the upcoming interventions/conservation solutions.
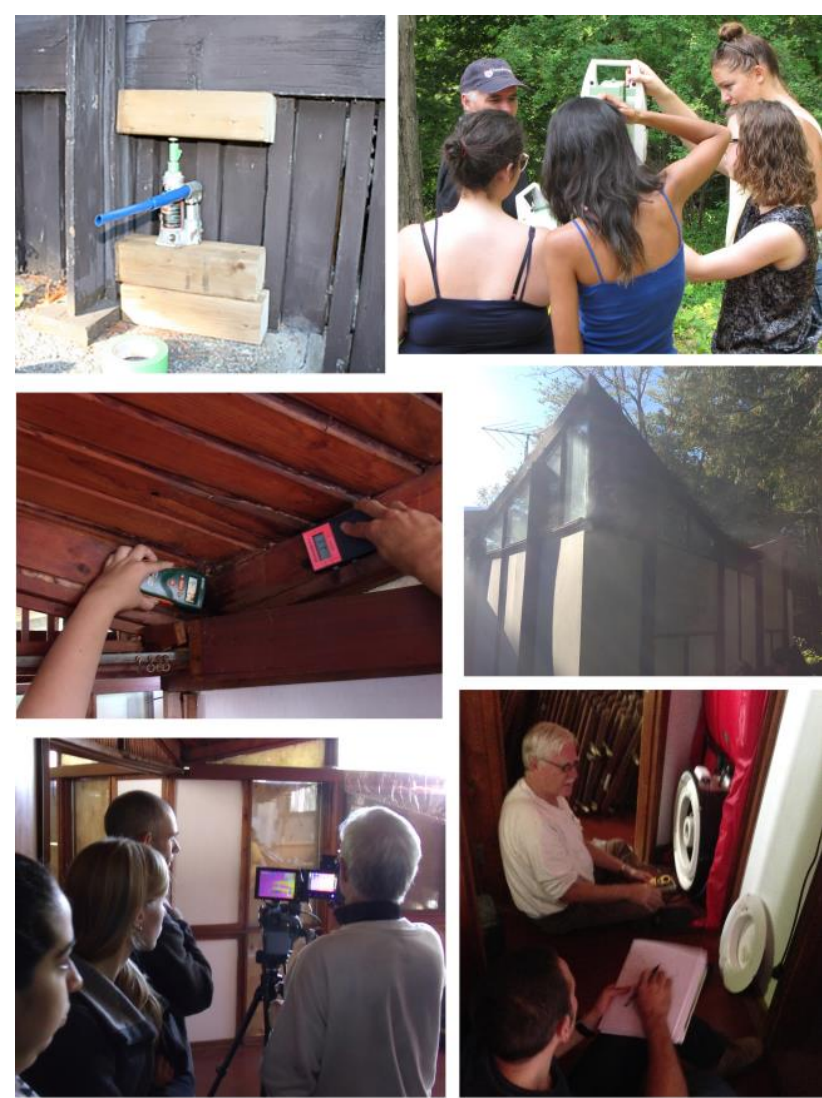

Figure 12. FSF Workshops: Platform Levelling, 3-D Scanning, Moisture and Metal Detection, Smoke Testing, Thermography and Blower door (left to right top down)

\section{SUMMARY}

\subsection{Application of the various documentation sets}

The initial result of the research undertaken -and the associated workshops- was the education of a large group of both Engineering and Architecture Conservation Students, and staff members of the FSF, as they received on site experience with leading edge technologies. The benefits of the collaboration led to a highly received thesis, source documentation for future works, data for cross referencing the existing conditions to asbuilt/designed data completed in the HSR.

3.1.1 The stabilization workshops were a trial to determine if the method proposed -derived from the information of the HSR Report- for levelling the buildings platform were 1) feasible and 2) affective. We proved in the workshops that it was feasible as a coordinated effort, and the 3-D scans could be used tell us if it is affective (the prior scans can be compared to a post workshop scan to determine the 'delta'). This is of course a simple example and it involves a great deal of work and processing power, however it is reversible and non-invasive; two critical goals of conservation practice.

3.1.2 Given the mandate of the FSF to both conserve and educate about conservation of our Modern Architectural Heritage, the collection and publication of the data sets from each of the above endeavours has been extremely valuable. Current staff continue to work on opportunities for additional applications of the data gathered to date, and to identify new 
required research based on knowledge gained from each of the above documents/data sets. The information is now available to the Foundation, our collaborating partners and our consultants, as they attempt to assess the viability of possible remediation techniques, or, just explain the house.

3.1.3 One of the unforeseen benefits has been the ability to use any of the data sets/investigative data to communicate in the best way possible the direct positive impact of many of the recommendations and in some cases even the visual comparison of 'before' and 'afters' even if originally the opposite (the afters of conservation often being close to the original conditions). In addition, some very useful secondary documentation was produced from the data and serves as communication devices to reveal the experiential qualities of the building through augmented virtual reality presentations. (A poster of the building assembly exploded and layered up from the Building Simulation, and then a short film created by Mr Jouan from the phogrammetry/3-D scans will have been used as part of an exhibition open to the public, supported by the FSF and the NCC, to celebrate Canada's $150^{\text {th }}$ during the summer of 2017.)

\subsection{Conservation Planning/Conservation Management Plan}

The sets of documentation referenced above will all be referenced in the ongoing creation of the Conservation Plan (CP) document for the Strutt House. Although the CP is to be based on the HSR's foundational construct; the document has evolved with data drawn from all of the workshops and each of the documentation/studies produced for them. The $\mathrm{CP}$ is to include a Conservation Management Plan.

We are certain that additional opportunities for applications of new documentation methodologies will continue to reveal novel ways to enhance the understanding and preservation of our heritage artifacts.

\section{ACKNOWLEDGEMENTS}

The Fondation Strutt Foundation acknowledges the support of: Brian Hierlihy of PTAH Consultants Inc., Architects; Professor Mario Santana and Pierre Jouan, of Carleton University CIMS Lab; the Getty Foundation's \#KeepingItModern Initiative; and, the Strutt House Project Committee Members for their contributions to this and all the ongoing collaborative efforts.

\section{REFERENCES}

About the National Capital Commission, 2017. http://www.nccccn.gc.ca/about-ncc

Strutt House, Federal Heritage Buildings, Directory of Federal Heritage Designations 2011,

http://www.pc.gc.ca/apps/dfhd/page_fhbro_eng.aspx?id=12611 (15 Mar 2012)

Getty Foundation, Keeping It Modern: 2015 Grants Awarded http://www.getty.edu/foundation/initiatives/current/keeping_it_ modern/grants_awarded_2015.html

PTAH Consultants Inc., Architects, 2012. Strutt House, 1220

Mountain Road, Gatineau Quebec, Heritage Structure Report.
Jouan, P., 2016. Building Information Modeling and the conservation of small scale wooden composite structures, learning from the case study of the "Strutt house". KU Leuven, Belgium.

Fondation Strutt Foundation, 2016. Strutt House, 1220, chemin de la montagne, Gatineau Quebec, Conservation Plan (Peer Review Draft).

\section{APPENDIX (N/A)}

